\title{
Awareness, Perceptions, and Attitude Regarding Coronavirus Disease 2019 (COVID-19) Among Ophthalmologists in Jordan: Cross-Sectional Online Survey
}

\author{
Hisham M Jammal (D) \\ Noor M Alqudah' \\ Yousef Khader $\mathbb{D}^{2}$ \\ 'Department of Ophthalmology, Faculty \\ of Medicine, Jordan University of Science \\ and Technology, Irbid, Jordan; \\ ${ }^{2}$ Department of Public Health, Faculty of \\ Medicine, Jordan University of Science \\ and Technology, Irbid, Jordan
}

This article was published in the following Dove Press journal: Clinical Ophthalmology

Purpose: COVID-19 pandemic is a serious public health concern, and the role of health care workers is essential in preventing spread. The study objective is to investigate awareness, perception, and attitude towards COVID-19 and infection control measures among ophthalmologists in Jordan.

Methods: The design of the study was a cross-sectional survey among Jordanian ophthalmologists. An online survey was sent to 197 ophthalmologists on March 23, 2020. Information on participants' socio-demographic characteristics, knowledge of clinical features of COVID-19, risk assessment and infection control measures for preventing disease transmission, and attitude towards treating patients with COVID-19 were collected.

Results: A total of 132 ophthalmologists (mean age 40.5 years) responded, 23 (17.6\%) had received training on infection control in ophthalmology. Most ophthalmologists were aware of COVID-19 symptoms and ways to identify patients at risk of having the disease, correctly reported modes of transmission and were aware of measures for preventing COVID-19 transmission in the ophthalmic setup. Social media was the commonest source of information on COVID-19 (75\%), and 38.2\% were not provided with instructions on infection control plan to reduce transmission of COVID-19. Most ophthalmologists $(79.5 \%)$ thought that the virus could be detected in tears, and $72.2 \%$ thought that red eye as a symptom of COVID- 19 . Conclusion: Ophthalmologists in Jordan were aware of the epidemiology of COVID-19 and related infection preventive measures. Knowledge was lacking regarding ocular aspects of the disease. Training on infection prevention needs to be improved. Access to guidelines from international ophthalmological organizations should be promoted and seeking updated literature from peer-reviewed journals needs to be encouraged.

Keywords: COVID-19, awareness, infection, Jordan, ophthalmologists

\section{Introduction}

According to the World Health Organization (WHO), coronavirus disease 2019 (COVID-19) is caused by a novel coronavirus, officially named as 'severe acute respiratory syndrome coronavirus 2 (SARS-CoV-2). The disease started as a pneumonia of unknown cause in Wuhan, China, in December 2019, ${ }^{1}$ and was declared by the WHO as public health emergency of international concern. ${ }^{2}$ It is a global health threat, as there have been 8,242, 999 cases confirmed worldwide ${ }^{3}$ as of June 18,2020 . In Jordan, there are currently 981 confirmed cases ${ }^{4}$ compared to
Correspondence: Hisham M Jammal Department of Ophthalmology, Faculty of Medicine, Jordan University of Science and Technology, Irbid, Jordan Email hmjammal@just.edu.jo 
246 cases at the time the survey was conducted. The incubation period for COVID 19 is up to 14 days, with a median of 5 days. $^{5}$

The virus spreads mainly from person to person through droplets contact with mucus membrane. ${ }^{6}$ It is also possible to spread via direct contact with a contaminated surface. Presumed asymptomatic carrier transmission of COVID-19 has been reported ${ }^{7,8}$. The virus is considered to be highly pathogenic and transmissible. ${ }^{9}$ Common symptoms include fever, cough, and fatigue. ${ }^{10}$ Several reports suggested that it can cause conjunctivitis in up to $30 \%$ of cases, ${ }^{11,12}$ in addition to that being isolated from conjunctival secretions. One case report found that viral RNA was detectable in ocular swabs many days after it was undetectable in nasal swabs. ${ }^{13}$ Angiotensin-converting enzyme 2 (ACE2) receptor and host cell transmembrane protease, serine 2 (TMPRSS2) are implicated in the process of viral attachment and interaction with ocular surface cells. ${ }^{14}$ This has led to a discussion on the possibility of SARS-CoV-2 being transmitted to a person via the conjunctival route ${ }^{15-18}$ This remains a controversial issue but the possibility of conjunctival transmission must not be ignored. $^{19}$

Health care workers are at increased risk of contracting COVID-19, and their safety is needed for the continuous provision of medical care of COVID-19 patients as well as preventing the transmission of the virus to other individuals. ${ }^{20}$ Ophthalmologists and other eye care providers are no exception to this, and they are particularly vulnerable. Sources of infection include droplet infection and to a lesser extent, touching contaminated instruments and objects. Because of the proximity (less than 1 meter) to the patient during slit-lamp examination or ophthalmoscopy, transmission of infection from an asymptomatic patient is a serious issue, considering that most COVID-19 patients are either asymptomatic or mildly affected. Furthermore, the possible presence of the virus in tears can inadvertently contaminate both the examiner and examination equipment. ${ }^{21}$

Ophthalmic patients are also at increased risk of COVID19. Many of them are elderly patients with reduced immunity. Diabetes and hypertension among such patients appear to increase the severity and complications of COVID-19. ${ }^{22}$ Ocular examination is particularly lengthy and requires that many patients stay for 15-30 minutes, usually in a crowded waiting area, in addition to excessive mobilization between different examination stations. This prolongs exposure time to possible airborne virus and increases the risk of spreading the infection to other patients and health care staff. Certain ophthalmic tests have been found to disrupt the tear film and cause microaerosol formation such as when performing noncontact "air-puff" tonometry. ${ }^{23}$ In view of the high infectivity of SARS-CoV-2, this may pose a real risk to all those present in the test area.

Many official international ophthalmologic organizations are continuously issuing updated clinical guidelines on COVID-19, detailing how to deal with the current COVID19 situation. $^{24,25}$ They focus mainly on educating ophthalmologists on COVID-19, detecting and stratifying at risk patients, dealing with each category, cutting or cancelling routine clinic visits, and nonurgent surgery, stressing the use of personal protection equipment (PPE), and adherence to proper disinfection methods. A helpful decision tree to facilitate the implementation of current guidelines in the ophthalmic setup is described by Gharebaghi. ${ }^{26}$ The objective of this study is to investigate the level of awareness, perception, and attitude about COVID-19 and infection control measures among ophthalmologists in Jordan.

\section{Materials and Methods Study Population}

The study population consisted of ophthalmology specialists and residents in their final year, practicing in Jordan. Four sectors were included: The Ministry of Health, the Royal Medical Services, the academic/university, and the private sector. The study was conducted on 23 March 2020 and the survey was available to participate in for a period of 2 days. A web-based survey using Google forms was constructed to collect data. Certain questions were derived from another survey related to dentists in Jordan. ${ }^{27}$ The sample of ophthalmologists was selected by asking a representative of each sector to disseminate the invitation to participate in the survey via a social media messaging application. A total of 197 ophthalmology doctors were selected based on their sector affiliation.

The survey was designed to ensure confidentiality of the information collected and the anonymity of all the study participants. The study was conducted according to the Helsinki Declaration principles. Ethical approval was obtained from the Institutional Review Board at Jordan University of Science and Technology. The ophthalmologists' participation and completion of the survey was regarded to be an informed consent to the study.

\section{Study Instrument}

After reviewing relevant literature and guidelines from two major official international ophthalmological 
organizations, ${ }^{24,25,28}$ a survey containing 35 multiple choice questions was constructed and written in English. The questions covered four major areas: 1) sociodemographic and professional characteristics, 2) level of awareness of clinical features (incubation period, symptoms of the disease, mode of transmission), 3) risk assessment of COVID-19 and infection control measures for preventing COVID-19 transmission, and 4) perception and attitude towards treating patients under different settings, related to COVID-19. The questions in the survey are available in Appendix 1.

\section{Data Analysis}

Data were analysed using IBM SPSS version 24. Descriptive statistics were used to describe items included in the survey. Means and standard deviations were used to describe the continuous variables and percentages were used to describe the categorical data.

\section{Results}

A total of 132 (100 males and 32 females) ophthalmology doctors out of 197 (67\%) completed the study survey. The mean (SD) age of participants was 40.5 (9.6) years (range: 27-68 years). Almost one-third $(48,36.4 \%)$ were working at the Royal Medical Services, followed by $41(31.1 \%)$ at the private sector, $23(17.4 \%)$ at the Ministry of Health, and $20(15.2 \%)$ at academic/university institutions.

The participants' demographic and professional characteristics are shown in Table 1 . The majority $(122,92.4 \%)$ of participants were either board certified or eligible and 10 $(7.6 \%)$ were senior residents, $23(17.6 \%)$ received training on infection control in ophthalmology, and 26 (19.7\%) attended lectures or training on COVID-19. The mean (SD) clinical ophthalmic experience was 12.7 (8.9) years.

\section{Sources of Information on COVID-19}

Regarding information on COVID-19 pertaining to ophthalmologists, 99 (75\%) doctors said they received information through social media websites and applications, and $21 \quad(15.9 \%)$ through the Jordanian Ophthalmological Society. Table 2 shows the sources of information on COVID-19.
Table I The Participants' Demographic and Professional Characteristics

\begin{tabular}{|l|l|l|}
\hline Variable & $\mathbf{n}$ & $\%$ \\
\hline Gender & & \\
Male & 100 & 75.8 \\
Female & 32 & 24.2 \\
\hline Age category & & \\
$\leq 35$ & 47 & 35.9 \\
$36-40$ & 32 & 24.4 \\
$>40$ & 52 & 39.7 \\
\hline Experience in years & & \\
$\leq 10$ & 69 & 52.3 \\
$>10$ & 63 & 47.7 \\
\hline Sector & & \\
Academic/University sector & 20 & 15.2 \\
Ministry of Health & 23 & 17.4 \\
Private sector & 41 & 31.1 \\
Royal Medical Services & 48 & 36.4 \\
\hline
\end{tabular}

Table 2 The Sources of Information on Coronavirus Disease 2019 (COVID-19) Reported by the Participants

\begin{tabular}{|l|l|l|}
\hline & $\mathbf{n}$ & $\%$ \\
\hline Social media & 99 & 75.0 \\
Google search & 82 & 62.1 \\
E-mail newsletters from official organizations & 68 & 51.5 \\
Local hospital & 31 & 23.5 \\
Peer-reviewed journals & 30 & 22.7 \\
Jordanian Ophthalmological Society & 21 & 15.9 \\
\hline
\end{tabular}

\section{Awareness of Clinical Features of COVID-19}

Regarding the incubation period, 93 (70.5\%) doctors reported 2-14 days. When asked about symptoms of COVID-19, fever and cough were reported by 131 (99.1\%) of ophthalmologists. Red eye was reported by 96 (72.2\%) doctors, and $116(87.9 \%)$ stated it may present with no symptoms. Other symptoms as reported by the participants are shown in Table 3.

Most doctors were able to identify common modes of transmission (Table 4). However, 109 (82.6\%) ophthalmologists considered finger contact with patients' tears and aerosol contamination to the conjunctiva as modes of transmission. 
Table 3 Symptoms of Coronavirus Disease 2019 (COVID-19) Reported by Participants

\begin{tabular}{|l|l|l|}
\hline Symptoms & $\mathbf{n}$ & $\%$ \\
\hline Fever & 131 & 99.2 \\
Cough & 131 & 99.2 \\
Shortness of breath & 129 & 97.7 \\
May present with no symptoms & 116 & 87.9 \\
Sore throat & 104 & 78.8 \\
Red eye & 96 & 72.7 \\
Diarrhea & 83 & 62.9 \\
Joint/muscle pain & 74 & 56.1 \\
Runny nose & 48 & 36.4 \\
Vomiting & 47 & 35.6 \\
Skin rash & 12 & 9.1 \\
\hline
\end{tabular}

Table 4 Modes of Transmission Reported by Participants

\begin{tabular}{|l|l|l|}
\hline Mode of Transmission & $\mathbf{n}$ & $\%$ \\
\hline Hand shaking & 131 & 99.2 \\
Touching surfaces (slit lamps and tables) & 131 & 99.2 \\
Coughing and sneezing & 126 & 95.5 \\
Finger contact with patients' tears & 109 & 82.6 \\
Aerosol contamination to the conjunctiva & 109 & 82.6 \\
\hline
\end{tabular}

\section{Awareness of Risk Assessment and Prevention of COVID-19 Transmission}

More than $85.6 \%$ of doctors reported the following to identify patients at risk of having COVID-19 infection: history of travel to high-risk areas of COVID-19, history of contact with possible infected patients, and presence of fever and presence of symptoms of a respiratory infection. Presence of acute conjunctivitis was reported by 56 (42.4\%) as indicative of a risk.

Whether patients attending for eye clinic appointments were at higher risk of contracting COVID-19, 78 (59.1\%) ophthalmologists answered yes, 28 (21.2\%) answered no, and 26 (19.7\%) did not know. Most doctors $(95,72 \%)$ reported that the virus could be detected in tears, and $(105,79.5 \%)$ reported that COVID-19 can be transmitted by aerosol contact with conjunctiva. However, 122 (92.4\%) agreed that the virus is very likely susceptible to the same alcohol- and bleachbased disinfectants that ophthalmologists commonly use to disinfect ophthalmic instruments and clinic furniture. Most doctors $(130,98.5 \%)$ reported that COVID-19 can be transmitted from an asymptomatic carrier to an ophthalmologist during routine eye exam. However, 78 (59.1\%) reported that they routinely used a slit lamp
Table 5 Participants Responses Regarding Measures That Should Be Taken to Prevent COVID-19 Transmission in the Ophthalmic Examination Room

\begin{tabular}{|l|l|l|}
\hline & $\mathbf{n}$ & $\%$ \\
\hline $\begin{array}{l}\text { Frequently clean hands by using alcohol-based hand rub } \\
\text { or soap and water }\end{array}$ & 130 & 99.2 \\
$\begin{array}{l}\text { Routinely clean and disinfect surfaces in contact with } \\
\text { known or suspected patients }\end{array}$ & 129 & 98.5 \\
$\begin{array}{l}\text { Put facemask on known or suspected patients } \\
\text { Avoid moving and transporting patients out of their } \\
\text { area unless necessary }\end{array}$ & 128 & 97.7 \\
$\begin{array}{l}\text { All health staff members wear protective clothing } \\
\text { Place known or suspected patients in adequately }\end{array}$ & 113 & 92.4 \\
ventilated single rooms & 106 & 80.3 \\
Taking Multivitamins to boost immunity & 59 & 45.0 \\
\hline
\end{tabular}

microscope with no clear plastic shield mounted on it. Table 5 shows the responses regarding measures that should be taken to prevent COVID-19 transmission in the ophthalmic examination room.

\section{Attitude Towards Managing COVID-19 Patients/Suspects}

Before listing patients in the clinic, doctors reported they would adopt the following measures: 122 (92.4\%) would ask the patient to bring no more than one accompanying person if necessary, $118(89.4 \%)$ would enquire if the patient or a family member has traveled to a high-risk area in the past 14 days, $116(87.9 \%)$ would reduce the total number of appointments in one day, $113(85.6 \%)$ would avoid listing more than one patient at the same time, and 107 (81.1\%) would ask the patient not to attend if they have cough or sore throat.

At the examination room, most doctors (130,98.5\%) believe that distancing patients far from each other, asking patients to wear masks in the waiting room, and applying alcohol to patients' hands helps to reduce disease transmission, while only $2(1.5 \%)$ doctors disagreed with the above measures as they may cause unnecessary anxiety.

Of those doctors working at clinics outside a hospital, $59(79.7 \%)$ doctors agreed to treat the patient who has cough after taking extra precautions and then ask the patient to be seen at a hospital for their symptoms, 5 $(6.8 \%)$ would refer the patient to the hospital without treating him/her, and $10(13.5 \%)$ would refuse treating the patient and ask him/her to leave the clinic. When asked to see an urgent case with no symptoms or risk factors for COVID-19, 59 (45\%) doctors reported that 
standard precautions that apply to all patient care is enough, $105(80.2 \%)$ reported that minimizing speech between the patient and the examiner during slit-lamp examination is appropriate, whereas 30 (22.9\%) thought that mask, gown and gloves are not routinely required for either the patient or doctor. When asked to see an urgent case with respiratory illness symptoms, but no fever or other COVID-19 risk factor, most doctors (108, 81.8\%) reported that they will require that patients and clinicians wear masks, 90.2\% recommended using gloves and proper eye protection, and $84.8 \%$ reported that examining room must be cleaned after examination.

In the case of a confirmed COVID-19 patient presenting to an outpatient clinic as an urgent case, 48 (36.4\%) doctors said they work at a public hospital and would follow its policy, $57(43.2 \%)$ would send the patient to a hospital equipped to deal with COVID-19 and urgent eye conditions, and $27(20.5 \%)$ would take all necessary precautions and treat the patient. Overall, 106 (80.3\%) doctors reported that they prefer to avoid encountering or examining a patient who is a suspect of COVID-19, and $117(88.6 \%)$ doctors reported that they would not permit their optician to examine patients with symptoms of respiratory tract infection.

\section{Perception of COVID-19}

COVID-19 was perceived as very dangerous by 74 (56.1\%) doctors, moderately dangerous by 56 (42.4\%), and not dangerous by only $2(1.5 \%)$ doctors. Nevertheless, nearly two-thirds $(91,68.9 \%)$ agreed that symptoms often resolve with time and do not require any special treatment. All the participants agreed that the ophthalmologist role in teaching others about COVID-19 is significant. The participants expressed different opinions regarding the option to run their clinics with local health authority's permission. Nearly half of them $(64,48.5 \%)$ would accept only urgent cases, 12 (9.1\%) would see all routine cases provided they are low risk (no symptoms or travel), $8(6.1 \%)$ preferred not seeing patients at all, and 48 (36.4\%) work at public hospitals and would therefore, follow the hospital's policy.

\section{Preparedness}

When asked if a clear strategy/infection control plan to reduce transmission of COVID-19 between patients or to ophthalmologists at the eye clinic was provided by the hospital/employing authority, more than one-third (50, $38.2 \%$ ) were not provided with such a plan, 29 (22.1\%) were given general verbal instructions, 25 (19.1\%) implemented a clear plan, and $16(12.2 \%)$ were given only written instructions to cancel routine consultations and surgeries, but no instructions on infection control measures. Eleven $(8.4 \%)$ doctors preferred not to answer.

\section{Discussion}

In this survey, a relatively acceptable response rate of $67 \%$ was attained. A small percentage of respondents had previous training in infection control in ophthalmology or attended lectures regarding COVID-19, and nearly $60 \%$ of them reported either being given no instructions, or just verbal instructions on dealing with current COVID-19 situation. Even though most ophthalmologists had shown good knowledge on preventive measures and infection control, this was a personal effort, and may explain why most doctors reported that the source of information they receive regarding COVID-19 was social media. This presents potential risks to patients and doctors related to information quality, patients' privacy, and potential legal issues. Guidelines on the use of social media for health care providers have been issued by many professional organizations worldwide, the objective of which is to provide proper advice on the use of such media and reduce the chances of committing professional mistakes when using or resorting to such media. ${ }^{29}$ Ophthalmologists are advised to make all efforts to ensure the information they derive come from credible and official sources. The educational role of local infection control committee is more informative, concise, relevant, and updated. Regular meetings to discuss updates and new emerging issues in infection control, and the inclusion of such measures in the residency curriculum may help ophthalmologists to be better prepared for possible outbreaks in the future. Clear and written plans for dealing with COVID-19, when circulated to all staff, can contribute to better and faster preparation in such situations.

The least used source of information obtained was from the Jordanian Ophthalmological Society. This highlights the need for the national societies to adopt a more active role during this emergency to deliver appropriate information on the current pandemic and evidence-based guidelines. Such guidelines could be derived and adapted from the continuously updated American Academy of Ophthalmology 24,28 and the Royal College of Ophthalmologists ${ }^{25}$ websites.

Most doctors identified the correct incubation period of 2-14 days, which helps define high risk/suspect patients 
who can be safely treated. However, as incubation periods of more than 14 days were recently reported, ${ }^{30}$ it might be wiser to practice extra precautions with suspected patients even after 14 days.

Common symptoms were identified correctly by most doctors, a key factor in identifying suspect patients. Interestingly, red eye was reported by $70 \%$ of ophthalmologists. However, a study of 1099 patients with COVID-19 reported by Guan et al showed that only $0.8 \%$ of the patients presented with red eye. ${ }^{31}$ This finding might be explained by the ophthalmologists' awareness of the common association of conjunctivitis with common respiratory virus infections. ${ }^{32}$ They were also able to identify common modes of transmission including the possibility of asymptomatic transmission. However, $82.6 \%$ thought that finger contact with patient's tears and aerosol contamination to the conjunctiva as a mode of transmission. This response is possibly due to ophthalmologists' awareness of the high rate of transmission via tears in adenovirus conjunctivitis, a common entity in ophthalmic practice. ${ }^{33}$ The rapidly emerging evidence regarding this issue is still unresolved, and most evidence so far is against the possibility of conjunctival or tear transmission. ${ }^{15,34,35}$ Nevertheless, most participants appear to assume that possibility and would therefore be more careful when examining patients' eyes.

Ophthalmologists' knowledge of measures to prevent transmission of COVID-19 was generally in accordance with the guidelines of the American Academy of Ophthalmology, which includes instructions on triaging patients attending the eye clinic, identifying high-risk patients, social distancing of patients, and minimizing speech during the examination. The lack of a clear plastic barrier on slit lamp microscope as reported by more than half of respondents can pose extra risk during patient examination, and the AAO clearly advises the use of such shields and that doctors need to protect their mouth, nose (e.g., an N-95 mask) and eyes (e.g., goggles or shield) when caring for patients potentially infected with COVID-19. ${ }^{24,28}$ The AAO also stresses the proper cleaning and disinfection of examination rooms and equipment using different types of disinfectants. A recent review ${ }^{36}$ suggested that surface disinfection with $0.1 \%$ sodium hypochlorite or $62-71 \%$ ethanol significantly reduces coronavirus infectivity on surfaces within $1 \mathrm{~min}$ exposure time and that a similar effect against the SARS-CoV-2 is expected. Most ophthalmologists in the survey identified the efficiency of the above disinfectants against the virus.

The attitude of ophthalmologists towards managing low risk, suspected or confirmed COVID-19 patients was also in line with the AAO guidelines. Most doctors reported they would follow certain measures before listing patients at the clinic, the purpose of which is to reduce the number of persons present at any time and to triage and exclude COVID-19 suspects.

When ophthalmologists were asked of what to do when they are assessing patients and a patient starts to cough while in the waiting room, all participants reported either not examining patients or examining them with extra precautions. Regarding these low-risk COVID-19 cases, the AAO recommends wearing a gown, surgical mask and eye protection, and to use N95 mask when a surgical procedure that will result in aerosol production is carried out, in addition to disinfection of the examination room. Most participants reported they would follow the same recommendations.

Contrary to AAO and other international guidelines, an alarming $20 \%$ of doctors reported they would treat urgent confirmed COVID-19 cases on outpatient basis after taking precautions. The AAO guidelines include managing such patients at a hospital-based setting that is equipped to manage both COVID-19 and eye conditions.

Almost two-third of doctors reported that most COVID-19 symptoms would resolve with no treatment. Yet, the disease was perceived as dangerous by most participants. This may be indicative of the ophthalmologists' awareness that the seriousness of COVID-19 epidemic lies in its ability to overwhelm the health care system, ${ }^{37}$ where in many cases, patients with urgent ophthalmic conditions become at risk of not obtaining proper timely care.

Being part of the medical community, most ophthalmologists agreed on their role in educating patients about COVID-19, to effectively reduce transmission and promote health.

One limitation of this study is that the survey was administered in English, which may constitute a language barrier to fully understand the questions by some respondents. In addition, the participants gave many responses regarding their source of information on COVID-19, which precluded knowing the primary or preferred source. Knowing this source might enable further assessment of the reliability and suitability of such source and give better advice on its use by ophthalmologists. One should 
consider that this study assessed awareness and perception of ophthalmologists regarding COVID-19 and it does not reflect their real practice as none of the ophthalmologists has treated any patients with COVID-19 yet.

In conclusion, ophthalmologists in Jordan were aware of different aspects related to COVID-19 including the incubation period, symptoms, mode of transmission, and infection preventive measures at the ophthalmic setup, but knowledge was lacking regarding ocular characteristics of the disease. Training on infection prevention and control needs to be stressed. Access to high-quality guidelines from international professional ophthalmological organizations should be promoted through the national ophthalmological society and seeking updated literature from peer-reviewed journals should be encouraged and disseminated.

\section{Disclosure}

The authors report no funding and no conflicts of interest in this work.

\section{References}

1. WHO. Pneumonia of unknown cause - China. WHO. Available from: http://www.who.int/csr/don/05-january-2020-pneumonia-of-unkowncause-china/en/. Accessed March 23, 2020.

2. IHR Emergency Committee on Novel Coronavirus (2019-nCoV). Available from: https://www.who.int/dg/speeches/detail/who-director -general-s-statement-on-ihr-emergency-committee-on-novelcoronavirus-(2019-ncov). Accessed March 23, 2020.

3. Coronavirus. Available from: https://www.who.int/emergencies/dis eases/novel-coronavirus-2019. Accessed June 18, 2020.

4. Jordan: WHO Coronavirus Disease (COVID-19) dashboard. Available from: https://covid19.who.int/region/emro/country/jo. Accessed June 18, 2020.

5. Lauer SA, Grantz KH, Bi Q, et al. The incubation period of coronavirus disease 2019 (COVID-19) from publicly reported confirmed cases: estimation and application. Ann Intern Med. 2020;172 (9):577-582. doi:10.7326/M20-0504

6. CDC. Coronavirus Disease 2019 (COVID-19) - Transmission. Centers for Disease Control and Prevention. Published March 17, 2020. Available from: https://www.cdc.gov/coronavirus/2019-ncov /prepare/transmission.html. Accessed March 23, 2020.

7. Bai Y, Yao L, Wei T, et al. Presumed asymptomatic carrier transmission of COVID-19. JAMA. 2020;323(14):1406-1407. doi:10.1001/ jama.2020.2565

8. Du Z, Xu X, Wu Y, Wang L, Cowling BJ, Meyers LA. Serial interval of COVID-19 among publicly reported confirmed cases. Emerg Infect Dis J. 2020;26(6). doi:10.3201/eid2606.200357

9. Han Y, Yang H. The transmission and diagnosis of 2019 novel coronavirus infection disease (COVID-19): a Chinese perspective. J Med Virol. 2020;92(6):639-644. doi:10.1002/jmv.25749

10. Report of the WHO-China Joint Mission on Coronavirus Disease 2019 (COVID-19). February 16-24, 2020. Available from: https:// www.who.int/docs/default-source/coronaviruse/who-china-jointmission-on-covid-19-final-report.pdf. Accessed March 23, 2020.

11. Xia J, Tong J, Liu M, Shen Y, Guo D. Evaluation of coronavirus in tears and conjunctival secretions of patients with SARS-CoV-2 infection. J Med Virol. 2020;92(6):589-594. doi:10.1002/jmv.25725
12. Wu P, Duan F, Luo C, et al. Characteristics of ocular findings of patients with coronavirus disease 2019 (COVID-19) in Hubei Province, China. JAMA Ophthalmol. 2020;138(5):575-578. doi:10.1001/jamaophthalmol.2020.1291

13. Colavita F, Lapa D, Carletti F, et al. SARS-CoV-2 isolation from ocular secretions of a patient with COVID-19 in Italy with prolonged viral RNA detection. Ann Intern Med. 2020. doi:10.7326/M20-1176

14. Napoli PE, Nioi M, d'Aloja E, Fossarello M. The ocular surface and the coronavirus disease 2019: does a dual 'ocular route' exist? J Clin Med. 2020;9(5):1269. doi:10.3390/jcm9051269

15. Zhou Y, Zeng Y, Tong Y, Chen C. Ophthalmologic evidence against the interpersonal transmission of 2019 novel coronavirus through conjunctiva. medRxiv. 2020. doi:10.1101/2020.02.11.20021956

16. Seah IYJ, Anderson DE, Kang AEZ, et al. Assessing viral shedding and infectivity of tears in Coronavirus Disease 2019 (COVID-19) patients. Ophthalmology. 2020;127(7):977-979. doi:10.1016/j. ophtha.2020.03.026

17. Seah I, Agrawal R. Can the Coronavirus Disease 2019 (COVID-19) affect the eyes? A review of coronaviruses and ocular implications in humans and animals. Ocul Immunol Inflamm. 2020;28(3):391-395. doi:10.1080/09273948.2020.1738501

18. Aiello F, Gallo Afflitto G, Mancino R, et al. Coronavirus disease 2019 (SARS-CoV-2) and colonization of ocular tissues and secretions: a systematic review. Eye. 2020;1-6. doi:10.1038/s41433-0200926-9

19. Lu C, Liu X, Jia Z. 2019-nCoV transmission through the ocular surface must not be ignored. Lancet. 2020;395(10224):e39. doi:10.1016/S0140-6736(20)30313-5

20. Chang D, Xu H, Rebaza A, Sharma L, Dela Cruz CS. Protecting health-care workers from subclinical coronavirus infection. Lancet Respir Med. 2020;8(3):e13. doi:10.1016/S2213-2600(20)30066-7

21. Kuo IC, O’Brien TP. COVID-19 and ophthalmology: an underappreciated occupational hazard. Infect Control Hosp Epidemiol. 2020:1-2. doi:10.1017/ice.2020.238

22. Fang L, Karakiulakis G, Roth M. Are patients with hypertension and diabetes mellitus at increased risk for COVID-19 infection? Lancet Respir Med. 2020;8(4):e21. doi:10.1016/S2213-2600(20)30116-8

23. Britt JM, Clifton BC, Barnebey HS, Mills RP. Microaerosol formation in noncontact "Air-Puff" tonometry. Arch Ophthalmol. 1991;109 (2):225-228. doi:10.1001/archopht.1991.01080020071046

24. Important coronavirus updates for ophthalmologists. American Academy of Ophthalmology. Published May 11, 2020. Available from: https://www.aao.org/headline/alert-important-coronaviruscontext. Accessed June 19, 2020.

25. Opthalmologists TRC of. COVID-19 clinical guidelines for ophthalmologists. The Royal College of Ophthalmologists. Published March 23, 2020. Available from: https://rcophth.ac.uk/2020/03/ covid-19-update-and-resources-for-ophthalmologists/. Accessed March 24, 2020.

26. Gharebaghi R, Desuatels J, Moshirfar M, Parvizi M, Daryabari S-H, Heidary F. COVID-19: preliminary clinical guidelines for ophthalmology practices. Med Hypothesis Discov Innov Ophthalmol. 2020;9(2):149-158.

27. Khader Y, Nsour MA, Al-Batayneh OB, et al. Dentists' awareness, perception, and attitude regarding COVID-19 and infection control: cross-sectional study among Jordanian dentists. J Med Internet Res. 2020;6(2):e18798. doi:10.2196/18798. Available from: https://publi chealth.jmir.org/2020/2/e18798/.

28. Alert: Important coronavirus updates for ophthalmologists. American Academy of Ophthalmology. Published March 22, 2020. Available from: https://www.aao.org/headline/alert-important-coronaviruscontext. Accessed March 24, 2020.

29. Ventola CL. Social media and health care professionals: benefits, risks, and best practices. $P$ T. 2014;39(7):491-520.

30. Jiang X, Niu Y, Li X, et al. Is a 14-day quarantine period optimal for effectively controlling coronavirus disease 2019 (COVID-19)? MedRxiv. 2020. doi:10.1101/2020.03.15.20036533 
31. Guan W, Ni Z, Hu Y, et al. Clinical characteristics of coronavirus disease 2019 in China. $N$ Engl J Med. 2020. doi:10.1056/ NEJMoa2002032

32. Belser JA, Rota PA, Tumpey TM. Ocular tropism of respiratory viruses. Microbiol Mol Biol Rev. 2013;77(1):144-156. doi:10.1128/ MMBR.00058-12

33. Seewoodhary R, Stevens S. Transmission and control of infection in ophthalmic practice. Community Eye Health. 1999;12(30):25-28.

34. Peng Y, Zhou Y-H. Is novel coronavirus disease (COVID-19) transmitted through conjunctiva? J Med Virol. 2020 doi:10.1002/jmv.25753

35. Yu Jun IS, Anderson DE, Zheng Kang AE, et al. Assessing viral shedding and infectivity of tears in coronavirus disease 2019 (COVID-19) patients. Ophthalmology. 2020;S0161642020303110. doi:10.1016/j.ophtha.2020.03.026
36. Kampf G, Todt D, Pfaender S, Steinmann E. Persistence of coronaviruses on inanimate surfaces and their inactivation with biocidal agents. $J$ Hosp Infect. 2020;104(3):246-251. doi:10.1016/j. jhin.2020.01.022

37. Gupta S, Federman DG. Hospital preparedness for COVID-19 pandemic: experience from department of medicine at veterans affairs connecticut healthcare system. Postgrad Med. 2020;1-6. doi: $10.1080 / 00325481.2020 .1761668$
Clinical Ophthalmology

\section{Publish your work in this journal}

Clinical Ophthalmology is an international, peer-reviewed journal covering all subspecialties within ophthalmology. Key topics include: Optometry; Visual science; Pharmacology and drug therapy in eye diseases; Basic Sciences; Primary and Secondary eye care; Patient Safety and Quality of Care Improvements. This journal is indexed on PubMed

Submit your manuscript here: https://www.dovepress.com/clinical-ophthalmology-journal
Dovepress

Central and CAS, and is the official journal of The Society of Clinical Ophthalmology (SCO). The manuscript management system is completely online and includes a very quick and fair peer-review system, which is all easy to use. Visit http://www.dovepress.com/ testimonials.php to read real quotes from published authors. 